\title{
Genetic variation of water caltrop (Trapa L.) in several Russian populations
}

\author{
A.E. Artyukhin ${ }^{1}$, E.V. Mikhaylova ${ }^{2 *}$, B.R. Kuluev ${ }^{1,2}$ \\ ${ }^{1}$ Bashkir State University, Ufa, Russia \\ ${ }^{2}$ Institute of Biochemistry and Genetics UFRC RAS, Ufa, Russia
}

DOI 10.18699/ICG-PlantGen2019-12

(c) Autors, 2019

* e-mail: mikhele@list.ru

\begin{abstract}
Water caltrop (water chestnut) (Trapa L.) is a valuable aquatic plant. Its seeds are edible and rich in protein and starch. The plant has become very rare and is now included in the Red List of Threatened Species in 36 regions of Russia and protected in most of the EU countries. The diversity of Trapa species is questionable, however, it is important for the protection of this plant. We studied genetic polymorphism of Russian populations and one of the largest European populations of Trapa L. in Skadar lake using different RAPD and ISSR primers and the sequencing of the ITS region of nuclear ribosomal DNA. In spite of morphological differences, especially in seed shape, only samples from the Far East, distinguished as T. maximowiczii, were significantly polymorphic.

Key words: Trapa natans; Trapa maximowiczii; water caltrop; water chestnut; RAPD; ISSR; ITS.
\end{abstract}

\section{Introduction}

Water caltrop (water chestnut) (Trapa L.) is a valuable aquatic plant. Its seeds are edible and rich in protein and starch. Antimicrobial compounds are found in the seed coat and can be used in medicine. Water caltrop has been widely cultivated by people since the Neolithic; however, on the territory of Europe and Russia, its population has decreased dramatically over the last century. The plant has become very rare and is now included in the Red List of Threatened Species in 36 regions of Russia and protected in most of the EU countries. In the USSR, around 30 species of Trapa L. were distinguished on the basis of morphological characteristics (Kuluev et al., 2017), but now most of them are considered synonyms. Molecular genetic methods, including AFLP, RAPD, and DNA sequencing were used to study Asian populations of water caltrop, and several species were described. In Europe, there is most probably only one polymorphic species, T. natans. Several poorly studied populations of water caltrop still remain in regions with the severe continental climate (Southern Urals and Siberia). It is not clear why it has been preserved on these territories. The diversity of Trapa L. is higher in the Russian Far East (Pshennikova, 2007; Bolotova, 2014). The study of the genetic and morphological diversity of water caltrop is important for the survival and recovery of the unique populations.

\section{Materials and methods}

Plant material was collected from four lakes in the Southern Urals (lakes Upkankul, Bilgilyar, Lebyazh'ye and Medvezh'ye) and Skadar lake (Montenegro). Leaf samples from four lakes in the Russian Far East (Pshennikova, 2007; Bolotova, 2014) and lake Solnechnoye in Siberia (Chepinoga et al., 2013) were provided by our colleagues. DNA was extracted from dried leaves by the CTAB method. We used universal RAPD primers AFK1, AFK3, OPAI-04, OPAI-05, OPC-06 and ISSR primers 814, ISSR11, ISSR16, ISSR22, ISSR24. Primer GGAAGTAAAAGTCGTAACAAG was used for ITS sequencing. The phylogenetic tree was gener- ated using DNASTAR software and statistically analyzed by bootstrapping.

\section{Results and discussion}

There were morphological differences between the plants. For example, in lake Lebyazh'ye water caltrop was found at two points. At the first one, leaves were larger and thicker, just like those in lake Medvezh'ye; however, at the second point, leaf rosettes were smaller, just like those in lakes Upkankul and Bilgilyar. There were also some differences in fruit shape. In lake Upkankul, we found several seeds with bifurcated horns (Figure 1). These seeds were propagated in an aquarium for DNA analysis.

The greatest diversity of morphotypes was detected in the Far East. DNA samples of the putative species T. pseudoincisia, T. manshurica, T. maximowiczii, T. japonica and T. korshinskyi were compared with samples from Skadar lake, Southern Urals and Siberia using RAPD and ISSR analysis. ISSR analysis was never performed on water caltrop before. All primers described were applicable and stably gave at least eight bands. However, only the samples from two different lakes in the Far East, distinguished as $T$. maximowiczii, significantly differed from the other samples. This result was reproducible with all the primers. Genetic polymorphism between other samples was not detected (Figure 2).

DNA of the plants from each habitat (Europe, the Southern Urals, Siberia and the Far East) were picked for sequencing (Figure 3), which confirmed the result of RAPD and ISSR analyses. T. maximowiczii is significantly distant from the other samples on the phylogenetic tree, and relations between the other samples are rather complicated. Sequencing reveals genetic divergence between plants collected at two different points of the same lake (Lebyazh'ye) and between plants with normal and deformed seeds from the same lake (Upkankul). However, this question requires further study. Without regard for deformed and probably mutant seeds (Figure 3(5)), it can be supposed that water 

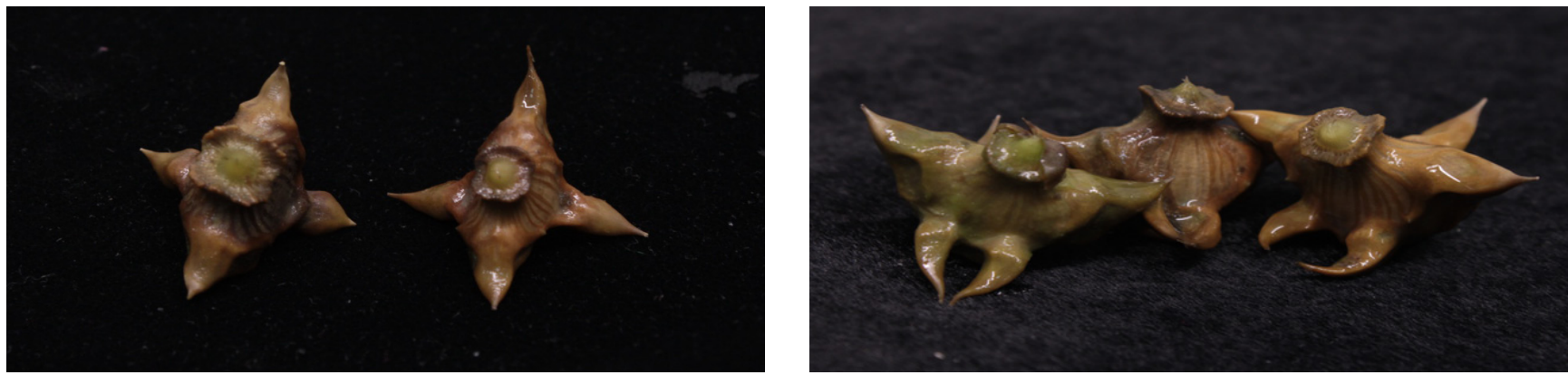

Figure 1. Normal and deformed seeds of water caltrop from lake Upkankul, Southern Urals.

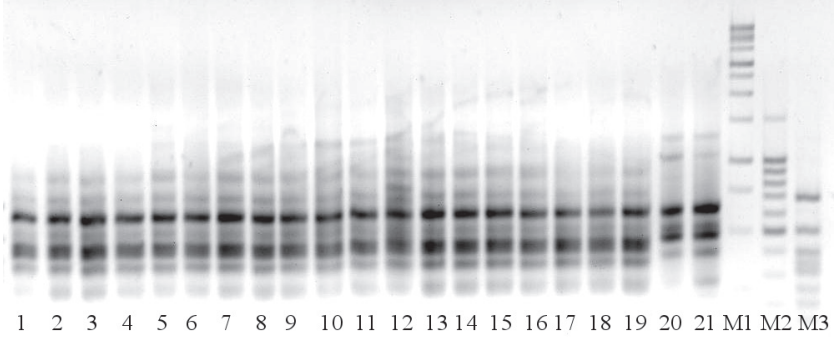

Figure 2. Results of DNA analysis with marker ISSR11. Sample 20: lake Lotos, Primorsky Krai, Russian Far East (T. maximowiczii); sample 21: noname lake, Amur oblast, Russian Far East (T. maximowiczii); 1-18: other samples. M1: 1-kb marker; M2: 100-bp marker; M3: 50-bp marker. caltrop from the Southern Urals is closer to the Siberian than to the European population. Noteworthy, during the isolation of the ITS region, T. maximowiczii demonstrated a double-band electrophoretic pattern, while the other samples gave one band. This is indirectly indicative of recombination events, and so these plants could be hybrids.

\section{Conclusions}

We obtained interesting results on genetic variation in several isolated Trapa L. populations. In general, samples from habitats with the severe continental climate (Southern Urals, Siberia) and samples from more favourable environments (Far East, Montenegro) demonstrate low levels of genetic polymorphism. The only exception is T. maximowiczii. It is possible that water caltrop has a great potential to adapt to different climatic conditions and can be reintroduced to its previous habitats from the South and be used as a food source again.

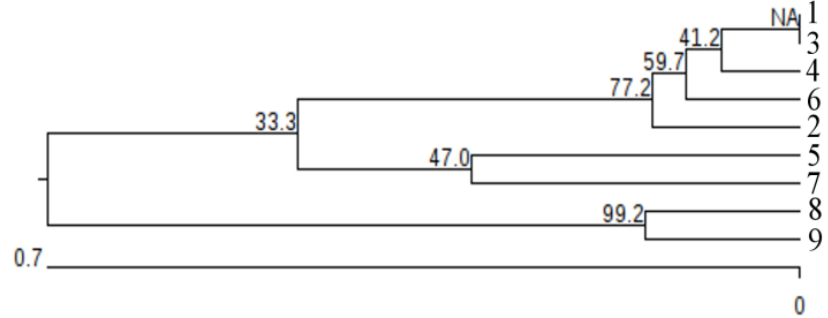

Figure 3. Phylogenetic tree of Trapa samples on the basis of ITS region sequencing:

1: lake Lebyazh'ye (point 1), Southern Urals, Russia; 2: lake Lebyazh'ye (point 2), Southern Urals, Russia; 3: lake Medvezh'ye, Southern Urals, Russia; 4: lake Upkankul (normal), Southern Urals, Russia; 5: lake Upkankul (mutant), Southern Urals, Russia; 6: lake Solonechnoye, Siberia, Russia; 7: lake Skadar, Montenegro; 8: lake Lotos, Primorsky Krai, Russian Far East (T. maximowiczii); 9: no-name lake, Amur oblast, Russian Far East (T. maximowiczii).

\section{References}

Kuluev B.R., Artyukhin A.E., Shevchenko A.M., Mikhaylova E.V. Water chestnut Trapa L.: biology, habitat and the study of its isolated populations in the lakes of Nurimanovsky district in the Republic of Bashkortostan. Biomics. 2017;9(2):101-118.

Pshennikova L.M. A new species of the genus Trapa (Trapaceae) from the Far East of Russia. Botanicheskii Zhurnal. 2007;92(1):159-160.

Bolotova Y.V. Distribution of Species of Genus Trapa L. (Trapaceae) in the Amur Region (Russian Far East). Vestnik of North-Eastern Federal University. 2014;11(2):22-28.

Chepinoga V.V., Bergmeier E., Rosbakh S.A., Fleckenstein K.M. Classification of aquatic vegetation (Potametea) in Baikal Siberia, Russia, and its diversity in a northern Eurasian context. Phytocoenologia. 2013;43(1-2):127-167.

Acknowledgements. The reported study was funded by Russian Science Foundation according to the research project No. 18-74-00056.

Conflict of interest. The authors declare no conflict of interest. 